\title{
Algo más de doscientos años de preocupación por la Naturaleza en Melilla y su tierra
}

\author{
Antonio González Bueno
}

"Hablad con cualquier hombre ávido de bienes o de gloria. Tiene previsto descansar cuando haya ejecutado tal o cual proyecto. Hablad con un cultivador de las ciencias y veréis que no desea otra cosa que la continuación de esos ocios estudiosos y lo mismo sucederá con el agricultor, lo cual parece indicar el disfrute de una felicidad más auténtica".

Jean Potocki

Viaje al Imperio de Marruecos realizado en el año $1791^{\prime}$

Ante todo quisiera agradecer la invitación de los organizadores de las "I Jornadas Medio-ambientales" para poder analizar con ustedes las causas históricas que han motivado a los naturalistas introducirse en el estudio del medio ambiente de estas tierras.

El título de esta sesión es "Algo más de doscientos años de preocupación por la Naturaleza en Melilla", se justifica porque, como veremos, en 1785 se dicta una Real Orden por la cual se funda en Melilla un Jardín Botánico, la primera instalación dedicada a estudios sobre la Naturaleza en estas tierras; pero la preocupación por conocer su medio natural, por sus riquezas naturales, para interpretarlo desde la óptica utilitaria propia del momento histórico al que voy a referirme en primer lugar ${ }^{2}$, subyace en el anhelo de la Corona Castellana por apoderarse del territorio.

1. De la tala al cultivo. Hacia un conocimiento del medio natural durante los siglos XVI a XVIII.

No es, desde luego, casual el interés de los Reyes Católicos por estas tierras en sus intentos de ensanchar sus dominios hacia el norte de Africa; tampoco decisivo, pero sí influyente, el informe anónimo de los exploradores de Hernando de Zafra, el Secretario Real, sobre las construcciones de cárabos y tarragabuts, tan perniciosas para los intentos españoles:

“... en todo el reino de Fez y de Tremecén (no existe) lugar en la costa de tal aparejo para los navíos como Vélez, por causa de la madera de los alerces, que

(1) Citamos por la versión de J.L. Vigil, en Laentes S.A., Barcelona, 1983. El texto en p. 18.

(2) Cf. el reciente estudio de L. Uneaga, La tierra esquilmada. Las ideas sobre la conservación de la naturaleza en la cultura española del siglo XVIII. Serbal-CSIC. Barcelona, 1987. 
los hay en Vélez, y muchos. Y no en otra parte de la costa, y quitados los moros de alli, no habrán manera como hicieran navios tan ligeramente como alli los hacen ..."3

Melilla sería la primera plaza ocupada en Africa; es conocido, la noche del 17 de septiembre de 1497 se posesionó de ella Pedro de Estopiñán para la Casa Ducal de Medina Sidonia; el Peñón de Vélez caería en 1508, tras la toma, el año anterior, de Mazalquivir.

Un informe militar pues, como en tantos otros casos, contiene las primeras noticias sobre la Naturaleza de estas tierras, y ésta es una de las constantes en el proceso gradual de aproximación al conocimiento de la Naturaleza melillense. La otra nota común en este proceso, a más de la citada participación militar y concomitante con ella, es la esencia fronteriza del territorio, lo que le otorga un carácter de avanzadilla no sólo geográfico, también legislativo en algunos momentos.

De entre las propuestas aprobadas durante el reinado de Carlos III tendentes a la modernización de la estructura sanitaria del pais ${ }^{4}$ merece ser traído a colación un reglamento firmado en Aranjuez, el 12 de mayo de 1784, donde se organiza el abastecimiento de las farmacias militares, hasta entonces servidas por asentistas y, desde la promulgación del reglamento, atendidas por boticarios militares directamente vinculados al Boticario Mayor de la Casa Real. La medida, de lógico encuadre en el programa de centralización borbónica, tiene para nosotros un doble interés; es de carácter experimental, el lugar elegido para iniciar el desarrollo del nuevo modelo son: "las tres plazas o presidios menores de Melilla, Peñón y Alhucemas" 5 y, lo que es más de destacar, el nuevo reglamento señala la autoridad sobre los demás del boticario destinado en Melilla, a quien conmina:

“... establecerá alli en Melilla su Elaboratorio y Almacén correspondiente para trabajar y custodiar toda la medicina y géneros simples que se necesiten para el surtimiento propio y de los otros dos botiquines" ${ }^{\prime}$.

He querido referirme a este artículo del reglamento de 1782 , porque en él está latente la creación de un Jardín Botánico en Melilla. No ha de olvidarse el papel

(3) El texto transcrito en J. Losana Méndez, Contribución de los farmacéuticos militares a la labor de España en el Norte de Africa, CSIC, Madrid, 1958, (cf. pp. 15-16). Sobre el papel jugado por los cronistas y el interés de Hemando de Zafra por las tierras norte-africanas cf. R. Femádez de Castro, "Los primeros exploradores españoles del Africa Mediterránea en el siglo XV". Selección de Conferencias pronunciadas en la Academia de Interventores durante el curso 1950-51, pp. 49-61. Tetuán, 1951.

(4) Un estudio detallado de la estructura sanitaria de la Época en M.C. Calleja, Las reformas sanitarias en la España ilustrada. Tesis doctoral, Facultad de Famacia, UCM. Madrid. 1988.

(5) Cf. R. Roldán Guerrero. La farmacia militar española en el siglo XVIII, Impr. A. Mazo, Madrid, 1925.

(6) "Estatutos o reglas bajo las cuales tiene por conveniente el Boticario Mayor del Rey Nuestro Señor se establezca, por ahora, el surtimiento de medicinas que Su Majestad se ha dignado mandar se haga por la Real Hacienda en las tres plazas o presidios menores de Melilla, Peñón y Alhucemas, para que aquellos habitantes las tengan de la mejor calidad y evitar los perjuicios que ha sufrido la misma Real Hacienda, explicados en los siguientes capítulos ..." El texto reproducido en R. Roldán, op. cit. nota 5, pp. 67-70. Nuestra cita en p. 68. 
renovador jugado por la Botánica en el modelo de reforma sanitaria borbónico en lo referente a la farmacia ${ }^{7}$; era pues de esperar se instalara el Jardín anejo al mencionado laboratorio, y así fue aunque no nos quede constancia en el ya comentado reglamento.

Nuestra afirmación tiene una doble base: de un lado la orden de traslado del "Laboratorio y Botica principal de los presidios menores de Africa" a Málaga, y de otro, las correspondencias mantenidas entre el boticario militar destinado en Melilla y Antonio Palau, segundo profesor del Real Jardín de Madrid y Juan Díaz, Boticario Mayor de la Casa Real.

En efecto, la orden de traslado, firmada en 24 de enero de 1787 prevee.

"Se transferirá a ella (a Málaga) D. Agustín de Yepes con cuanto tiene en Melilla, dejando alli solo lo necesario para la servidumbre de aquella Botica. despidiendo el jardín grande que está fuera de la muralla, después de sacar de él todas las plantas para poner en el pequeño inmediato a la Botica las que quepan, y transportando las restantes al jardin que debe establecerse en Málaga"8.

Más vitales que esta fría orden de traslado son las cartas enviadas por Vicente Zenitagoia a Antonio Palau, durante la corta estancia del primero en Melilla, pues aquí habría de morir en 1786 , al volar la pólvora de repuesto que había en la muralla de la Plaza $^{9}$. La correspondencia localizada en el archivo del Real Jardín de Madrid ${ }^{10}$ es suficientemente elocuente de los problemas derivados de esta situación de frontera a la que me referí hace algunos momentos.

Voy a permitirme leerles algunos fragmentos de estas cartas, no sin antes recordarles que entonces Melilla no se encontraba en buenas relaciones con el pueblo marroqui, de ahí las poco gratas alusiones de nuestro boticario a sus próximos ${ }^{11}$.

"Si sus tareas le permitiesen (escribe en agosto de 1784) espero me remitirá algunas semillas para el establecimiento de Jardín Botánico en esta que no se puede salir al campo que su aspecto manifiesta tendrá muchas preciosidades, pero la barbaridad de nuestros vecinos nos obliga á no sacar al descubierto ni aún la cabeza conteniéndonos en el corto recinto de las murallas en que sólo he examinado las pocas plantas que anoto abajo y no más pues todo está seco" ${ }^{\prime 2}$.

(7) De interés al respecto el reciente estudio de F.J. Puerto Sarmiento. La ilusión quebrada, Botánica, sanidad y política científica en la España ilustrada. Serbal-CSIC. Barcelona, 1988.

(8) Transcrita en op. cit. nota 4, pp. 70-71. También en J.L. Valverde \& P. Arrebola Nacle, "El laboratorio de Málaga como centro de aprovisionamiento de medicamentos a las boticas de los presidios menores de Africa". Ars Pharmaceutica 24(2) pp. 161-168. Granada, 1983.

(9) Cf. M.E. Alegre Pérez, Veinticinco años en la Real Botica (1783-1808). Tesis doctoral, Facultad de Farmacia, UCM. Madrid, 1976.

(10) Archivo Real Jardín Botánico de Madrid (Arch. RJB) leg. I,21,8. Contiene tres cartas, fechadas en Melilla, en 26-VIII-1784, 6-XII-1784 y 16-VII-1785.

(11) Cf. el estudio introductorio de S. Barberá en su edición del texto de Aly Bey, Viajes por Marruecos. Editora Nacional. Madrid, 1984. La introducción supone las pp. 1-109 del volumen; de interés también la bibliografía alli reseñada.

(12) Correspondencia V. Zenitagoia con A. Palau, Melilla, 26-VIII-1784. (Arch. RJB leg. I,21,8,8). 
Un interés por las plantas no circunscrito a las profesionales, sino vivo en el resto de la comunidad melillense, así, por ejemplo, en el Gobernador de la ciudad:

“... el Gobernador de esta (escribe en diciembre de 1784) se me ha interesado por algunas flores si $\mathrm{Vm}$. me hiciese el favor de encargar al tío Pedro ó Ambrosio añadan aquellas que á ellos les parezca le estimaré" 13 .

Para seguir la misiva quejándose de las dificultades inherentes al trabajo en aquel lugar:

"En cuanto a las que se crían aqui es tan corto el término que poseemos que medio tiro de fusil le atraviesa sin poder salir de ai afuera y aún en esse á veces con muchos trabajos por esta canalla vecina que tenemos ..." 14 .

Pero centrémonos en el Jardín de nuestro interés, del que en verdad poseemos pocos datos: sabemos estuvo instalado en un huerto propiedad de Antonio López Curiel, pues así consta en su Real Orden fundacional de 10 de enero de $1785^{15}$ y, según se desprende de la correspondencia que venimos comentando, llegó a tener hasta 100 especies distintas, aunque no todas locales ni tampoco bien acondicionadas. Sabemos, por una notificación de V. Zenitagoia a Juan Díaz que, además de los envíos de semillas del Real Jardín, contó con otras procedentes de la Real Botica: esta nota, fechada en Melilla el 22 de julio de 1785 y hoy conservada en el Archivo de Palacio (Madrid ${ }^{16}$, contiene una lista de lo sembrado en el Jardín, gran parte de ello de interés medicinal, pero no todo.

Digamos el comentario de $\mathrm{V}$. Zenitagoia, fiel reftejo del estado del Jardín, a más de interesante en otros aspectos relativos a la Naturaleza melillense:

"He recibido las semillas que por manos de D. Gregorio (alude a Gregorio Bañares ${ }^{17}$ ) se ha servido remitirme de las que algunas hé sembrado ya en el nuevo Jardín que en el ia solo se contarán como unas 76 o 77 plantas de especies: varias se me han perdido que completaban más de 100 á causa de tanto insecto como cría esta tierra que en ninguna lo he visto en miriada, como tampoco que las cabras se coman Beleño, mesembrianthemum, salicornia y

(13) Ib. Melilla, 6-XII-1784. (Arch. RJB leg. $1,21,8,9$ ).

(14) Ib. Melilla, 6-XII-1784. (Arch. RJB leg. I,21,8,9).

(15) Sobre este tema $c f$, además de M.E. Alegre Pérez op. cis. nota 9, el trabajo de P. Arrebola Nacle, Los Servicios farmacéuticos de los Presidios Menores de Africa (1784-1885). Tesis doctoral, Faculuad de Farmacia, Universidad de Granada. Granada, 1981. Agradecemos a la Dra. Rosa M. Basante Pol las gestiones realizadas para proporcionamos la documentación presentada por la Dra. Pilar Arrebola.

(16) Archivo de Palacio Real (Madrid). Sección I. "Suministros de Medicinas y varios". (Carta de D. Vicente Zenitagoia a D. Juan Díaz, Melilla, 22-VII-1785).

(17) Sobre Gregorio Bañares (1760-1824) cf. G. Gómez Renedo, Estudio de la obra cientifica de Gregorio Bañares. Memoria de licenciatura, Facultad de Farmacia, UCM. Madrid, 1983. En 1784 superó las pruebas para ejercer la profesión farmacéutica y en 1789 habría de ingresar en la Real Botica; es un joven Gregorio Bañares quien serviría de enlace entre Madrid y Melilla. 
otras plantas semejantes como aquí y depende de las poquissimas que se crían en el corto districto que tenemos y no se encuentran otro pasto que esse, el año pasado pude salir alguna vez fuera de las murallas que se manifiesta un campo delicioso pero este año ni asomar la cabeza para mirar afuera, han hecho dos ataques á tiro de pistola de nuestros fuertes que es cosa vergonzosa que asi se diga y cada dia nos van reduciendo y estrechando mas" ${ }^{18}$.

El Jardín melillense tuvo una vida breve, en 1787 fue trasladado a Málaga, se cierra con ello una primera etapa, parca en realizaciones concretas, pero de interés en el contexto de la renovación científica propuesta por los españoles ilustrados.

Debemos esperar hasta fines del siglo XIX para contemplar el florecimiento de los estudios sobre el medio natural de estas tierras.

\section{Naturalistas en Melilla: El estudio científico del medio natural como ar- gumento en la colonización del territorio (1860-1912)}

La penetración iniciada por los españoles en el territorio del Imperio Xerifano, tras la declaración de guerra de octubre de 1859 , no tuvo repercusiones entre los escasos y aislados naturalistas españoles. Sería a fines del siglo cuando, en grupos ya organizados de naturalistas ${ }^{19}$, se despertaría el interés por estas tierras, coincidiendo entonces con una corriente intervencionista plasmada, entre otras realidades, en la creación de la Sociedad de Africanistas y Colonialistas, en 1884.

Los grupos africanistas, inician, a partir de 1904, un movimiento colonizador hacia los territorios norte-africanos, conocido como "penetración pacífica" (1904-1910), perfectamente definido en los trabajos de Víctor Morales Lezcano, entre cuyas actividades se encuadra el fomento de las expediciones científicas por parte de los Centros Comerciales Hispano-marroquies ${ }^{20}$.

Este interés, marcadamente económico, por conocer la geografía y las riquezas naturales de los territorios de este lado del Estrecho, obtiene respuesta inmediata en la colectividad científica española, con un aumento, aunque no lineal, de las publicaciones referidas a su historia natural entre 1894 y 1936.

En septiembre de 1894, Salvador Calderón presentó ante la Sociedad Española de Historia Natural un estudio sintético sobre el medio natural de las Chafarinas ${ }^{21}$; como

(18) Correspondencia V. Zenitagoia con A. Palau. Melilla, 16-VII-1785. (Arch. RJB leg. I,21,8,10).

(19) Recordemos que durante la segunda mitad del siglo XIX ocurre un florecimiento en el estudio de las Ciencias Naturales propiciado, sin duda, por la libertad ideológica disfrutada durante el sexenio revolucionario y el clima de estabilidad reinante durante la Restauración (cf. J.M. López Piñero, Medicina y Sociedad en la España del siglo XIX. Sociedad de Estudios y Publicaciones. Madrid, 1964). Este ambiente naturalista es mantenido, entre otras, por la Sociedad Antropologica Española (1865), la Sociedad Española de Historia Natural (1871) o la Institución Libre de Enseñanza (1876) (cf. D. Núñez Ruíz, La mentalidad pasitiva en España: Desarrollo y crisis. Tucar ed. Madrid, 1975).

(20) Seguimos a V. Morales Lezcano, El colonialismo hispano-francés en Marruecos (1898-1927). Siglo XXI ed. Madrid, 1976.

(21) S. Calderón, "Las Chafarinas". Boletin Sociedad Española de Historia Natural. Serie 2. (Bol. SEHN. ser. 2), 3 pp. 303-316. Madrid, 1894. 
justificación del área estudiada utiliza las premisas defendidas por Castor Amís en el Congreso Español de Geografía Colonial y Mercantil celebrado en Madrid ese mismo ano de 1894:

“Constituye (...) un precioso refugio para las naves que pueden aguantarse en las aguas de Melilla, y en el porvenir pueden ser asiento principal de nuestra influencia en Marruecos ... adquiririan extraordinaria importancia convertidas con poco cosie en un gran puerto militar y de refugio cuando se construya una plaza de guerra en el promontorio del Cabo de Agua y un establecimiento comercial en la desembocadura del Muluya. Por el momento son muchas las difcultades que se oponen a la realización de tan laudables propósitos y entre ellos el gran desconocimiento que hay del Riff por falta de exploración y estudio; pero de todos modos es indudable que nuestra colonización por la parte septentrional de Africa debe tener como base á Ceuta. Alhucemas, Melilla é Islas Chafarinas, y que la empresa exige crear buenos puertos y dar á estas plazas una cierta autonomía" 22 .

El texto, más político que científico, se completa con los datos proporcionados por Miguel Iborra, farmacéutico militar con destino en Melilla, y con otros de una memoria inédita de Vicente Chiralt; en ambos casos insuficientes para cubrir los objetivos científicos supuestamente perseguidos por el autor, pero sobrados para la conclusión final obtenida:

"... creo que lo indicado es suficiente para probar la utilidad de una excursión cientifica realizada en condiciones de recoger observaciones y ejemplares para hacer la historia natural de este pequeño pedazo de tierra española, que pudiera quizás un día adquirir una importancia extraordinaria" ${ }^{23}$.

La idea lanzada por Salvador Calderón sería acogida por la Sociedad Española de Historia Natural diez años después, cuando la situación político-social la hiciera viable.

Las Islas Chafarinas tuvieron ese carácter de terra ignota señalado por Salvador Calderón durante poco tiempo; los militares ubicados en ellas se encargarían de descubrirlas en lo natural; la estancia de Luis Bescansa Casares ${ }^{24}$, un farmacéutico militar destinado entre 1900 y 1901 en su hospital, le permitió herborizar el material necesario para presentar su tesis doctoral, la primera leída sobre el medio natural de estas tierras, defendida en la Universidad Central el 21 de junio de 1902; lleva por título "Herborizaciones fanerogámicas en las Islas Chafarinas y sus inmediaciones del Campo Moro" 25; en la introducción al catálogo florístico se aboga por el interés de este medio

(22) Op. cit. nota 21, p. 306.

(23) Op. cit. nota 21, p. 316.

(24) Sobre Luis Bescansa Casares cf. R. Roldán Guerrero, Diccionario biogrdfico y bibliografico de autores farmacéuticos españoles T. 1, p. 362 Madrid, 1963.

(25) Impr. "El Eco de Galicia". 1908. 23 pp. Sobre el mismo tema había dado a la Imprenta otro texto similar, "Apuntes para la flora de las Islas Chafarinas y campo moro fronterizo". Revista Farmacia Militar I pp. 85-87, 102-104. Madrid, 1902. 
natural, incitando a su estudio para el que cuenta con la colaboración de algunos marroquies del territorio próximo:

"El tema (...) me lo sugirieron las expediciones que he podido hacer mediante la amistad del Kaid de la kábila de Kabdana llamado Arfouf y algún otro moro vecinos de las Islas Chafarinas; ya en compañia de mi compañero D. Carlos Vilaplana, Médico Militar, ya con los demás oficiales de la guarnición, el sargento de Marina y el intérprete de la Plaza" 26.

insistiendo, pese a todo, en la particularidad fronteriza del territorio explorado

"... la exposición que corre el que intenta pisar territorio Marroqui ..."27.

recuerda en la presentación de su trabajo ante el tribunal.

En marzo de $1905^{28}$, a petición de Manuel Martínez de la Escalera, se iniciaron gestiones para realizar una excursión, la anual de la Sociedad Española de Historia Natural, al norte de Africa; se nombró al efecto una comisión formada por Salvador Calderón, Ignacio Bolivar y Blás Lázaro. A comienzos de abril ${ }^{29}$ se encuentra ya ultimado el borrador de una muy particular sección formada en el seno de la Sociedad, pero independientemente de ella en muchos aspectos.

La "Comisión para la Exploración del Noroeste de Africa" nace

"con entera independencia de la gestión ordinaria de la Sociedad, y muy principalmente en lo relativo á la recaudación de los recursos que á ella se destinen y á la inversión de los mismos ..." 30

y además formada por personas, de influencia política conocida, no relacionadas con la Española de Historia Natural, sobre las que recae toda la responsabilidad gestora:

"Para la organización de las exploraciones, recaudación e inversión de los fondos que á ellas se destinen y representar a la Sociedad oficialmente en todo cuanto se relacione con este proyecto, se constituirá una Junta o Comisión permanente bajo la presidencia del socio protector (nombrado al efecto) Excmo. Sr. D. Manuel Allende Salazar (liberal, ex-ministro de Instrucción Pública) quien designará las personas que hayan de constituirla; dicha Junta estará revestida de amplias facultades para resolver sobre cuanto se relacione con la exploración del Noroeste de Africa" ${ }^{31}$.

(26) L. Bescansa Casares, Herborizaciones fanerogámicas en las Islas Chafarinas y sus inmediaciones del campo Moro, s.l., 1908, p. 3.

(27) Op. cit. nota 25, p. 3.

(28) "Comunicaciones" Bol. SEHN. ser 2. 5 p. 134. Madrid, 1905.

(29) "Correspondencia" Bol. SEHN. ser 2. 5 pp. 186-187. Madrid 1905.

(30) Op. cit. nota 28, p. 186. Acuerdo primero.

(31) Op. cis. nota 28, p. 186. Acuerdo quinto. 
Los miembros elegidos para formar la citada Comisión ponen de manifiesto el interés, y la influencia, de los partidarios de la ocupación pacífica de la zona: los duques de Alba, Luna y Medinaceli y el marqués de Santa Cruz coparan las vicepresidencias, sólo, de manera testimonial, se reservará una para Santiago Ramón y Cajal ${ }^{32}$, la tesorería recaerá sobre el Marqués de Urquijo; tan sólo los vocales parecen interesados y responsables en la parte científica del proyecto, y aún entre ellos es posible encontrar intereses políticos, como en Luis Bahía Urrutia, atraido por la situación agrícola desde su sillón de las Cortes ${ }^{33}$.

Los fondos económicos no se hicieron esperar, primero la subvención Real $(5.000$ ptas.), luego las de los propios miembros políticos de la Comisión ${ }^{34}$, instituciones interesadas en el proceso colonizador, como el Ministerio de Estado (10.000 ptas.), Banco de España (5.000 ptas.), Casino de Madrid (1.000 ptas.) o la Asociación de Ganaderos (500 ptas.) y particulares vinculados a grupos neocolonialistas ${ }^{35}$. La creación de esta Comisión no se debe al azar, es lógica respuesta a una situación social donde lo marroquí cobra excepcional interés; no sólo en el caso español, también en el francés, conviene recordar que precisamente este año de 1905 el Ministerio francés de Instrucción Pública destina, por vez primera, un fondo especial para una recién fundada "Misión científica a Marruecos" 36 .

La primera expedición organizada por la Comisión del Noroeste de Africa sería de interés zoológico, dirigida por Manuel Martínez de la Escalera, se centrará en la fauna de Mogador ${ }^{37}$, pero entre los objetos expuestos en el museo de Ciencias Naturales de Madrid, con motivo de dar publicidad a las actuaciones de los expedicionarios, figuran materiales melillenses:

"Unos 450 minerales, rocas y fósiles de Ceuta, Melilla, Islas Chafarinas, Isla Alborán, Peñón de Vélez de la Gomera, Isla de Alhucemas y territorios rifeños de Cabo de Agua, Bocoya, Mezquita, Benisicar y Frajana"38.

(32) Presencia casi obligada; recordar que fue también presidente honorario de una "Federación de las Asociaciones Hispano-Sefardíes de Marruecos" junto a Alfonso XIII y el Conde de Jordana, entre otros (cf. V. Morales Lezcano, op. cit. nota 20, p. 121).

(33) "Comisión del Noroeste de Africa". Bol. SEHN. ser. 2. 5 pp. 293-295. Madrid. 1905. "El Secretario dio cuenta de haber quedado constituida la Comisión para la exploración del Noroeste de Africa", desde entonces sus vocales figurarán junto a los de la Junta directiva de la Sociedad.

(34) M. Allende Salazar colaboró con 500 ptas., el Duque de Medinaceli con 2.500 pts. (cf. Bol. SEHN. ser. 25 p. 295. Madrid, 1905).

(35) Se señalan las aportaciones de Nicolás M. Urgoiti, Carlos Barranco y S. Estefani (cf. Bol. SEHN. ser. 2.5 p. 295. Madrid, 1905).

(36) "Comunicaciones" (Emilio Ribera), ("Partidas del presupuesto de Instrucción Pública en Francia"). Bol. SEHN. ser. 25 p. 297. Madrid, 1905.

(37) Los preparativos de la expedición son de especial interés: "han salido para Mogador provistos abundantemente de cartas de presentación para los cónsules y agentes diplomáticos, que nos han sido facilitadas por el Ministerio de Estado, y otras de recomendación para los judios más influyentes, donadas a nuestro consocio (M. Marínez de la Escalera) por el Dr. Pulido". (Bol. SEHN. ser, 25 p. 325. Madrid, 1905). Muy significativo el agente oficioso de España en Marraquex (cf. T. García Figueras, "Los naturalistas españoles en Marruecos". Las Ciencias Naturales en el Africa Hespérica pp. 169-224. Alta Comisaría de España en Marruecos. Tetuán, 1948. (El dato recogido en p. 180).

(38) Cf. Bol. SEIN. ser. 2, 5 p. 413. Madrid, 1905. 
precedentes de las exploraciones de Lucas Fernández $\mathrm{Navarro}^{39}$, catedrático de cristalografía en la Facultad de Ciencias de Madrid y un adelantado de los estudios geológicos en el norte de Africa ${ }^{40}$. El mismo reconoce el carácter pionero de sus trabajos en un interesante "Plan de una exploración geológica al Noroeste africano" ${ }^{41}$; allí insiste, entre otros aspectos, en el interés geológico del litoral rifeño: "entre el cabo de Agua frente á las Chafarinas y la isla Iris, a Poniente del Peñón de Vélez de la Gomera" 42, la zona estudiada por él mismo durante estos años. Pero lo realmente innovador de este Plan, y que supone una excepción a los comentarios generales en este momento de claro apoyo económico a las investigaciones sobre la Naturaleza norteafricana, es su crítica sobre la imposibilidad de elaborar un proyecto de investigación suficientemente profundo.

"Además, dicha limitación y determinación en el plan, siempre muy difícil de fijar en las tareas de esta índole, llega á ser en nuestro caso verdaderamente imposible, porque carecemos del dato del que habian de partir todos los cálculos, del conocimiento de los recursos con que habremos de contar. Por desgracia lo único seguro que desde luego podemos afirmar en este punto, es que el auxilio oficial será muy inferior á lo que la empresa demanda, y que habremos de marchar mucho más despacio de lo que á los intereses de la ciencia y de la patria convendrí" 43 .

Improvisación en el planteamiento de las investigaciones, y esto cuando L. Fernández Navarro alude al campo geológico, de un enorme interés económico debido a su vinculación con las explotaciones mineras, uno de los mayores incentivos, junto al ferrocarril, para el capital neocolonial ${ }^{44}$

La segunda de las expediciones patrocinadas por la Comisión para la Exploración del Noroeste de Africa sería también zoológica, tendría lugar durante el verano de 1907 y su objetivo sería el Atlas, pero pese a los reiterados intentos de M. Martínez de la Escalera, la zona quedaría sin estudiar; asi se justifica en su informe:

"La situación política es muy complicada y difícil sin que se la considere grave; la sobreexcitación de los naturales es tan grande, que por los caminos se ven correr caballos abandonados y asomar las cabezas de los moros por las bardas

(39) Ib. p. 325.

(40) Sobre la obra de Lucas Fernández Navarro of. el artículo de E. Portela Marco en J.M. López Piñero \& al., Diccionario histórico de la ciencia moderna en Esparia. t. 1, pp. 333-335. Ediciones Península. Barcelona, 1983.

(41) L. Femśndez Navarro, "Plan de una exploración geológica del Noroeste africano". Bol. SEHN. ser. 26 pp. 301-306. Madrid, 1906. Alll reconoce: "Habiéndome correspondido el honor de iniciar, en lo que a Geologia se refiere, la importante labor de exploración emprendida en Africa por nuestra Sociedad, ..." Op. cit. p. 301. Madrid, 1906.

(42) Op. cil. nota 41, p. 301.

(43) Op. cit. nota 41, p. 305.

(44) Cf. V. Morales Lezcano, op. cit. nota 20. En especial "Las Minas del Rif y el capital financiero peninsular (1906-1930)". pp. 69-87. 
de los corrales, escondiéndose en seguida que son vistos; las autoridades impidén cuanto pueden el paso de los europeos, para evitarse complicaciones. aunque en realidad nada ocurre" ${ }^{\prime 45}$.

Apenas unos meses después, a comienzos de 1908, las tropas españolas ocupan la Restinga y Cabo de Agua; los militares disfrutaban de una fuerte influencia política sobradamente analizada por Manuel Tuñón de Lara. "Una guerra en Marruecos se «mascaba»"46.

\section{Naturalistas en una sociedad militar (1912-1927)}

Aún en 1910, Odón de Buen se refería, con motivo de la inauguración del Museo Oceanográfico de Mónaco, a los escasos conocimientos disponibles sobre la Naturaleza norte-africana y a la obligación moral de España por presentar, ante el colectivo científico, resultados de investigaciones concretas.

“Ocupamos puntos críticos en la cuenca mediterránea, y el mundo científico tiene derecho á exigirnos el estudio concienzudo y detenido de nuestras costas, para que no pueda afirmarse, con motivo, que no contribuimos al progreso científico y nos limitamos á ser clientes de la cultura mundial" ${ }^{47}$.

Será precisamente Odón de Buen el encargado de dirigir, en abril de 1913, una excursión científica por el Rif, a instancias de la Sociedad Española de Historia Natural y del Museo de Ciencias de Madrid; le acompañaría Arturo Caballero en calidad de botánico; la expedición tendría como centro Melilla, y desde aquí se organizarían excursiones al monte Gurugú, Nador y Cabo de Agua. Del diario de viaje de A. Caballero me permitiré leerles algunos párrafos; en ellos está latente un modelo distinto de trabajar en el campo, fiel reflejo de la nueva situación de la plaza y su tierra; la situación fronteriza cobra aquí todo su significado al encontrarse ya la zona bajo la jurisdicción militar:

"Una vez en Melilla (7 de abril) y obtenida la autorización indispensable de la primera autoridad militar de aquella región, empezamos á poner en práctica el plan proyectado (...) El día 25 de abril embarcamos en Melilla en el correo de Cabo de Agua, y en las primeras horas de la tarde desembarcamos en este punto, donde, apenas sin descansar, una vez obtenido el indispensable permiso del señor Comandante del fuerte, nos dedicamos a herborizar los alrededores de éste (...) A la mañana siguiente, acompañados por dos soldados indígenas que galantemente puso a nuestra disposición el jefe militar, Sr. Civantos, salimos por la orilla del mar en dirección al río Muluya, con el objeto de herborizar en

(45) Bol. SEHN. ser. 2, 7 p. 268. Madrid, 1907.

(46) M. Tuñón de Lara, La España del siglo XIX. Ed. Laia. Barcelona. 1980. El entrecomillado en L. 2, p. 186.

(47) O. de Buen, "Plan de trabajos comunes en los laboratorios biológico-marinos del Mediterráneo". Bol. SEHN. ser. 2, 10 pp. 275-282. Madrid, 1910. El texto citado en p. 282. 
sus orillas (...) Al día siguiente, 27 de abril, de vuelta en Melilla y después de una última y rápida visita á los alrededores próximos a la plaza, preparamos el material herborizado para remitirlo á España en cuyo puerto de Málaga desembarcamos el 1 de mayo" 48 .

A. Caballero realizaría un nuevo viaje de estudio por Melilla entre mayo y junio de 1915, financiado entonces por la Junta para Ampliación de Estudios ${ }^{49}$.

La ictiología cobró especial importancia en esta expedición de $1913^{50}$, no debe olvidarse la formación oceanográfica de su director ${ }^{51}$, sus datos sobre la fauna marina melillense complementan los escasos aportados por Rafael de Buen tras sus campañas en diciembre de 1909 y algunos anteriores del propio Odón de Buen. Con todo la mayor aportación en este campo se debe a Luis Lozano Rey quien, en 1921, publicó en el volumen de Memorias consagrado por la Sociedad Española de Historia Natural al Protectorado de Marruecos, un detenido estudio de las colecciones de peces recogidos en las costas de Melilla y conservados en el Museo de Ciencias Naturales de Madrid, procedentes de éstas y otras expediciones realizadas por Luis Lozano entre 1908 y $1916^{52}$.

Su texto nos habla de las riquezas faunísticas de esta zona, si bien ya en 1921, eleva una protesta contra el abuso de explotación de la plataforma continental:

"Estas cargas de pescado (alude a las existentes en el mercado de Melilla) (...) las obtenían por medio de cartuchos de dinamita lanzados al mar, desde lo alto de las rocas (del cabo de Tres Forcas), en lugares donde se puede acechar el paso de las bandas de peces. El brutal empleo de la dinamita (...) es sin duda la causa principal de que el fondo contiguo a Tres Forcas no sea el paraíso de vitalidad que debiera si se dejase a la Naturaleza florecer a su antojo y se practicase la pesca utilizando únicamente artes nobles" 53 .

El autor propone un sistema alternativo de pesca, utilizando las peculiares condiciones topográficas de la Mar Chica. Los informes sobre la Bocana utilizados por Luis Lozano para conformar su sistema alternativo de pesca, fueron elaborados por un militar, el teniente de navio Mazarello.

Esta situación de militarización del territorio que venimos comentando, resultó favorable para el estudio de la Naturaleza, en contra de lo que podría pensarse en un

(48) A. Caballero, "Enumeración de las plantas herborizadas en el Rif". Memorias Sociedad Española de Historia Natural (Mem. SEHN) 8 pp. 241-Madrid, 1915. El diario en las pp. 242-246.

(49) A. Caballero, "Excursión Botánica a Melilla en 1915". Trabajos Museo de Ciencias Naturales (Serie Botánica) 11 pp. 1-39. Madrid, 1927.

(50) Los resultados ictiologicos serian publicados por O. de Buen, "Peces de la costa meditertánea de Mamuecos". Bol.SEHN. ser. 2, 12 pp. 153-166. Madrid, 1912.

(51) Sobre la obra científica de O. de Buen cf. el artículo de J.M. López Piñero en J.M. López Piñero \& al., op. cit. nota 40, L 1, pp. 136-138.

(52) Luis Lozano Rey, "Datos para la iatiología marina de Melilla". Mem. SEHN. 12, pp. 121-204. Madrid, 1921.

(53) Op. cil. nota 52, p. 127. 
ambiente de posible peligro bélico; precisamente porque serian los farmacéuticos militares, como ya esbozamos al comienzo, quienes proporcionarían importantes datos sobre la historia natural melillense.

Durante el año 1912, Xiberta Raig, farmacéutico militar destinado en Melilla, envió plantas a Pio Font Quer para su determinación ${ }^{54}$, no era una novedad para el también militar catalán quien ya antes había recibido otras colecciones de Larache remitidas por Francisco Pérez Camarero ${ }^{55}$, y de hecho esta labor recolectora desarrollada por los sanitarios del ejército sería considerada básica para la elaboración de una flora del Mediterráneo occidental, tema abordado por $\mathrm{P}$. Font Quer durante estos años. Así valora éste los envíos recibidos:

"Todos esos envios son con frecuencia ricos en cosas curiosas y en novedades, y nos dicen lo mucho que podrian hacer para el estudio de la flora de Marruecos, los farmacéuticos destinados en las farmacias militares de Melilla. Zeluán, Nador, Ceuta. Tetuán, Arcila, Larache y Alcazar, además de los de las Chafarinas, Peñón y Alhucemas, que son los que existen en la actualidad" 56.

Me he querido detener en este comentario porque en él se resume un método de trabajo propio de los territorios con acceso dificultoso; se recurre a personal alli ubicado, incitándole a que proporcione los materiales necesarios para abordar el estudio del medio natural, pero la labor de determinación es realizada por científicos profesionalmente capacitados distintos de estos recolectores ocasionales.

Este modelo, que bien podría pensarse es el empleado en el caso de estas tierras, no es aplicado más que en contadas ocasiones ${ }^{57}$. El medio natural en Melilla es estudiado in situ por científicos especializados, algunos de ellos militares, pese a las incomodidades derivadas de su condición de frontera. El propio P. Font Quer, de quien procede el comentario anterior, realizaría excursiones botánicas por Melilla y su área próxima durante el año 1929.

Antes de él lo haría Enrique Gros, el herborizador del Museo de Ciencias de Barcelona, aunque con poco éxito ${ }^{58}$. En mayo de 1926, José Sanjurjo, general en jefe del Ejército de Africa, dictó un bando ${ }^{59}$ prohibiendo la permanencia y circulación de cualquier civil por los territorios de Aixdir, Tensaman y Beni-Tuzin, salvo permiso especial

(54) P. Font Quer, "Sobre la flora de Melilla". Bol. SEHN. ser. 2, 16 pp. 285-287. Madrid, 1916.

(55) P. Font Quer, "Plantas de Larache". Bol. SEHN. ser. 2, 14 Pp. 425-430. Madrid, 1914.

(56) P. Font Quer, op. cir. nota 54, p. 286.

(57) Las recolecciones micológicas llevadas a cabo por A. Caballero y determinadas por R. Gonź́lez Fragoso, por ejemplo, (Cf. R. González Fragoso, "Algunos Micromicetos de los alrededores de Melilla (Mamuecos), recolectados por el profesor D.A. Caballero". Mem. SEHN. 8 pp. 335-383. Madrid, 1916. Ib., "Algunos Micromicetes más de los alrededores de Melilla (Marruecos) recolectados por el profesor A. Caballero". Bol. SEHN. ser. 2, 17 pp. 78-83. Madrid, 1917).

(58) Cf. la correspondencia mantenida entre P. Font Quer y E. Gros durante la estancia del segundo en Melilla (1926). Archivo Instituto Botánico de Barcelona, sin catalogar (Arch. IBB, s.c.).

(59) El bando, firmado en Tetuán el 31-V-1926, fue reproducido repetidamente en El telegrama del Rif, nosotros lo hemos leído en un reconte de prensa enviado por E. Gros a P. Font, en carta fechada en Melilla a 8VI-1926 (Arch. IBB, s.c.). 
expedido por el Alto Mando, éste no fue concedido a E. Gros pese a contar con el apoyo de los farmacéuticos militares destinados en Alhucemas ${ }^{60}$. P. Font Quer escribe al respecto en carta a C. Pau:

"... lo de Gros es un verdadero calvario. Hay que creer en su mala sombra. Ayer recibi un telegrama suyo en el cual me anuncia su regreso a Málaga. desde Melilla, sin haber podido llegar a Alhucemas por no haber recibido la debida autorización" 61 .

Esta vez la empresa era subvencionada por la Junta de Ciencias Naturales de Barcelona.

En 1926 , y pese a su reticencia inicial ${ }^{62}$, P. Font Quer se decide a emprender el estudio de la zona española en Marruecos; las campañas serían autofinanciadas con la venta del material herborizado, nace así el "Iter Maroccanum" (1928-1932), el más completo de los estudios botánicos emprendidos en esta zona por investigadores españoles.

El propio P. Font relata así la génesis de su idea:

"Libre de la empresa del Herbario de España desde 1926 (...) vi posible la realización ha tiempo deseada de una campaña botánica en el Rif. Por otra parte, la pacificación de la zona española de Marruecos iba por tan buen camino que todo hacía pensar en la posibilidad de emplear desde el punto de vista histórico natural no sólo las costas rifeñas, sino también las montañas del interior, territorios hasta hoy desconocidos botánicamente (...) Quise todavia realzar el valor de la colección que yo pudiese formar en el Rif (...) y conté con el ofrecimiento que había recibido de mi sabio amigo el Dr. Carlos Pau, tan experto conocedor de la flora del Norte marroqui, como lo es de la española (...) Decidido a la realización de mi proyecto se me presentó otro problema (...) ¿a qué precio podría señalarse a cada unidad o pliego? (...) fijé el precio de cada uno en 1,25 pesetas" 63 .

La cifra calculada sobre un total de 700 números para ocho colecciones $(5.600$ pliegos) supondria unos ingresos de 7.000 pesetas, con ellos habria de abastecerse de papel, etiquetas impresas y costear los viajes, durante tres meses, de él y E. Gros por el Rif. La cantidad parece adecuada a los gastos ocasionados; el propio P. Font había

(60) "... aprovechando amables ofrecimientos de mis compañeros farmacéuticos militares pasará a Axdir. donde residirá (E. Gros) una quincena. Ello me dará material para mis notas sobre la fiora occidental". Correspondencia de P. Font a C. Pau, Barcelona, 16-IV-1926 (Arch. IBB, s.c.).

(61) Correspondencia P. Font a C. Pau, Barcelona, 16-VI-1926 (Arch. IBB, s.c.).

(62) "Celebro cuanto me dice de sus proyectos de Marruecos; realmente es tentador. Pero en España, ifalta tanto por explorar! Cada vez que llegan a mí esas noticias de viajes al Rif, siento envidia de los viajeros. $Y$ cada vez la misma reflexión me detiene en mis entusiasmas: antes España". Correspondencia P. Font Quer a C. Pau, Barcelona, 23-XI-1920. (Arch. IBB, s.c.).

(63) P. Font Quer, Organización y desarrollo de una campaña botánica en el Rif. Madrid, 1927. Citamos por una tirada aparte de los artículos aparecidos en el Boletín de Farmacia Militar $5(60)$. El texto en pp. 4-5. 
solicitado a la Junta para Ampliación de Estudios, en marzo de 1915, una pensión para trabajar durante un mes en Larache, entonces desglosó así el presupuesto:

"450 ptas. en viajes / 300 ptas. en residencia / 200 ptas. en guias / 50 ptas. en papel / Total 1.000 ptas" $^{64}$.

Ahora se triplicaba el tiempo de estancia y habria de aumentarse en mucho los gastos de papel, además de incluir la impresión de las etiquetas; la vida en Melilla no era barata, recordemos el comentario de E. Gros en su frustrado viaje de 1926:

“... los gastos aqui son muy grandes el hospedaje me cuesta 8 pesetas diarias para estar medianamente decente" 65 .

Una vez aceptada su oferta de venta por los principales centros botánicos europeos y americanos, y obtenido el permiso de la Junta de Ciencias Naturales de Barcelona (institución de la cual dependía profesionalmente P. Font) inicia la primera de sus exploraciones por el Rif, la entrada al territorio sería Melilla:

"El (día) 9 de abril saludé a mis compañeros los farmacéuticos militares de aquella plaza (Melilla): visité al subinspector, Sr. Robles, en la Farmacia del Buen Acuerdo, donde acudieron todos los demás. Charlamos buen rato de cosas agradables y se me dieron consejos para la mejor marcha de mi empresa. El Sr. Robles quiso acompañarme a la oficina del Estado Mayor de la Comandancia General, donde nos autorizaron al recolector del Museo y a mí para pasar a la zona de vanguardia, donde deseaba herborizar. Por la tarde, nuestro compañero Revert me llevó a la Oficina de intervenciones, y alli me dieron recomendaciones para los puestos de policía de la zona de vanguardia. Guardo un grato recuerdo de ese día pasado en Melilla y de los compañeros farmacéuticos militares, que me colmaron de atenciones. Al dia siguiente, el 10 de abril, por la mañana, partimos en "auto" público para Villa Sanjurjo, y no fuimos por mar porque era mi deseo ver tierra y hacerme cargo, siquiera fuera sumariamente, de la vegetación del Rif oriental" 66.

Los minuciosos apuntes de P. Font Quer y la amplia serie de correspondencia conservada en el Instituto Botánico de Barcelona ${ }^{67}$ permite conocer el material transportado para realizar estas investigaciones:

"Consistía éste en 10 prensas grandes de madera y tuercas metálicas, cuatro prensas de hierro para el campo, 1.000 almohadillas y 2.500 pliegos de papel

(64) Archivo del Consejo Superior de Investigaciones Cientificas - CSIC - (Madrid). Sección Junta para Ampliación de Estudios (JAE). "Papeles pertenecientes a P. Font Quer".

(65) Correspondencia E. Gros a P. Font, Melilla, 8-VI-1926 (Arch. IBB, s.c.).

(66) P. Font Quer, op. cit. nota 54, p. 7.

(67) Agradecemos al Dr. Josep M. Montserrat las facilidades proporcionadas para consultar el archivo del Instituto Botánico de Barcelona. 
estraza, unos 12 millares de hojas de papel blanco y de periódicos para guardar las plantas preparadas, azadillas, cuartillas, libros, cordel, etc., hasta media tonelada de peso en total" ${ }^{\prime 68}$.

No es momento ahora de reconstruir estos viajes, cinco el total ${ }^{69}$, el tercero de ellos, en 1929, dedicado a las tierras próximas a Melilla, más cuando sus opiniones acerca de estas campañas fueron publicadas en varias revistas, entre ellas el melillense "Telegrama del Rif" "70, a ellos remito al interesado en estas expediciones, baste decir que esta labor botánica fue básica para la elaboración del catálogo sintético de las plantas de Marruecos, firmado por E. Jahandiez y R. Maire, con la colaboración de P. Font Quer en alguno de sus volúmenes ${ }^{71}$.

Las investigaciones emprendidas por P. Font Quer cobraron suficiente importancia para que fuera reconocido, a nivel internacional, como el especialista español en esta flora ${ }^{72}$.

\section{Naturalistas en una sociedad civil (1927-1936)}

Tras la pacificación del territorio en 1927 , los estudios sobre la Naturaleza melillense comienzan a ser abordados por el personal civil ubicado en la ciudad, fundamentalmente médicos y profesionales de la enseñanza. Sirva como ejemplo el prólogo del Hno. Mauricio, de la doctrina cristiana, a su opúsculo publicado en colaboración con otro lasallista, el Hno. Sennen, titulado "Catálogo de la flora del Rif oriental y principalmente de las cábilas limitrofes con Melilla", impreso aquí, en Melilla, el año 1934.

"Para contribuir al conocimiento de la flora de Melilla y de su territorio y aportar nuestra cooperación a tan útil estudio, empezamos a principios de 1928 una investigación metódica y entusiasta de las plantas que espontáneamente crecen en nuestro suelo (...) aprovechando la era de paz que aquí disfrutamos (...) En esta labor cientifica, ni un momento interrumpida, a pesar de lo poco que

(68) P. Font Quer, op. cit. nota 54, p. 9.

(69) La reconstrucción de los "Iter Marocanum" de P. Font Quer constituirán un próximo número de los Treballs de l'Institut Botánic de Barcelona sobre el que actualmente trabajamos.

(70) Así sus cinco notas sobre la vegetación del Rif Central aparecidas en El Telegrama del Rif (Melilla) entre los días 26-VII / 28-VII / 30-VI / 2-VIII / 4-VIII-1927, resumen de su viaje de 1927. Otros antículos aparecidos en Monitor de la Farmacia y Terapéutica (Madrid), Africa (Ceuta), Boletín de Farmacia Milisar (Madrid) o Diario Español de Alhucemas (Alhucemas), además de los aparecidos en revistas científicas. Una relación de estos trabajos, tanto científicos como divulgativos, puede encontrarse en $A$. Bolos \& O. Bolos, "Biografta de P. Font Quer". Collectánea Botánica 7 (1) pp. 3-45. Barcelona, 1968.

(71) E. Jahadiez \& R. Maire, Calalogue des plantes du Maroc 3 vols. Alger, 1931-1943. En el volumen I se hace constar la colaboración de J.A. Battandier, L. Ducellier, L. Emberger \& P. Font Quer. Esta obra es base de otra posterior: R. Maire \& al. Flore de l'Afrique du Nord. Paris (1952), en 1987 apareci6 el vol. 16.

(72) Además de los comentarios vertidos en las oo.pp. cil. nota 62, cf. la opinión de J. Mas Guindal en La Flora Curso de Conferencias sobre el Protectorado español en Marruecos V. Publicaciones de la Real Sociedad Geográfica. Madrid. 1930. 
favorecen los tiempos que corremos, han cooperado todos los profesores del Colegio, especialmente los Hermanos Maximiliano y Lázaro, que en sus correrías tanto se preocupan de tan laborioso estudio (...) Con todo, reconocemos, que siempre que en nuestras excursiones hemos solicitado algún servicio o ayuda a los valientes oficiales de nuestro sufrido Ejército, nos han atendido con toda deferencia y se han esforzado por complacernos y ayudarnos" 73 .

El trabajo aludido fue ampliado en otro posterior, "Campagnes botaniques au Maroc oriental de 1930 a 1935 des Fréres Sennen et Mauricio EE.CC." (Madrid, 1936), en ambos, y en otros artículos de estos autores aparecidos en distintas revistas científicas, se presenta muy completa la flora de estas tierras, si bien bajo el particular concepto de especie mantenido por el hermano Sennen.

También herborizadas por maestros melillenses son las plantas estudiadas por C. Pau en 1935, se deben a Anselmo Pardo y a su compañero Martí y fueron recolectadas durante los años 1932 y $1933^{74}$. Este cambio de herborizadores, docentes ahora en lugar de los farmacéuticos militares del período anterior, se explica por la nueva situación creada en la ciudad: se ha logrado la pacificación de la zona.

Restan aún muchos aspectos que deben ser estudiados, he obviado la infatigable labor divulgadora de Joaquín Más Guindal, a quien se deben más de un centenar de trabajos de diversa índole, relativos a estas tierras ${ }^{75}$, la desarrollada en este mismo ámbito por Rafael Candel Vila ${ }^{76}$ desde su cátedra de Ciencias Naturales en el Instituto de Segunda Enseñanza de Melilla; tampoco me he ocupado de sociedades como la Excursionista melillense, dedicada a conocer la Naturaleza de este espacio físico durante la década de los veinte, en este siglo; ni tampoco he prestado la debida atención a los esfuerzos de la Dirección General de Colonización por promover, tanto el conocimiento de estas realidades desde las enseñanzas impartidas en las Granjas Agrícolas, entre otras la instalada en Melilla, como por controlar la conservación de las especies arbóreas a las que se refieren sendos reglamentos promulgados en 1914 y $1929^{77}$.

Quede como idea final que el medio natural de Melilla, empieza a ser bien conocido

(73) Hno. Sennen \& Hno. Mauricio, "Catálogo de la flora del Rif oriental y principalmente de las cábilas limírofes con Melilla". Melilla, 1934. El texto en pp. VII-VIII.

(74) Sobre la obra de F. Sennen $c f$. I. Teodoro Luis FSC. O Botánico Lassalista Fr. Sennen Canoas (Brasil), 1961. También P. Font Quer, "Etienne-Marcellin Granier Blanc, Frére Sennen, E.C." Cavanillesia 8 (9. 10) pp. 163. Barcelona, 1938.

(75) C. Pau, "Relación de las plantas que los profesores de primera enseñanza, don Anselmo Pardo y Sr. Martí herborizaron en las inmediaciones de Melilla en los años 1932 y 33". Boletín Sociedad Ibérica de Ciencias Naturales 33 pp. 96-102. Zaragoza, 1935.

(76) Una bibliografía de J. Mas Guindal en "Datos bibliográficos del Dr. Mas-Guindal". Anales Real Academia de Farmacia 11 (l) pp. 20-45. Madrid, 1945. También J. Menéndez Amor, "El Dr. Joaquín Mas-Guindal Messeguer". Bol. SEHN. ser. 2, 43 pp. 89-92. Madrid, 1945. De interés su personal "Autobiografía. Servicios, publicaciones, costumbres, anécdotas". Farmacia Nueva 9 (93) pp. 611-617, 9 (95) pp. 671-673, 10 (96) pp. 57-60, 10 (97) pp. 121-124, 10 (98) pp. 187-190, 10 (99) pp. 251-252, 10 (101) pp. 364-366, 10 (104) pp. 534-535, 10 (105) pp. 590-593, 10 (108) pp. 43-48. Madrid, 1944-1946.

(77) Una bio-bibliografía de R. Candel Vila en R. Roldán Guerreo, op. cit. nơta 24, t. 1, pp. 522-523. R. Candel Vila fue catedrático de Ciencias Naturales en el Instituto de Melilla antes de cursar estudios de Tarmacia en Granada. 
desde los años centrales de nuestra década de los treinta. Detendremos aquí nuestro periplo por el pasado, tras la Guerra Civil, a partir de la década de los cincuenta ${ }^{78,79}$ estas tierras vuelven a ser estudiadas por naturalistas, la mayor parte de ellos siguen con nosotros, suya es la palabra.

Nada más, muchas gracias.

(78) $C f$. los datos proporcionados por J. Mas Guindal, op. cit. nota 72.

(79) No quiero silenciar la activa labor de Juan Rullant Basset, médico y malacólogo asentado en Melilla, cuya amplia colección, de más de 30.000 ejemplares, ha sido estudiada por diversos especialistas, entre ellos $R$. Zariguiey (cf. R. Zariguiey Alvarez, Crustáceos decópodos recogidos por el Dr. Rullant en aguas de Melilla. Tetuán, 1952). El doctor Rullant comenź su labora recolectora en 1945. 